\title{
Evaluating Fertilizer Application Strategy for Improving Crop Yields and Reducing Mineral Nitrogen Leaching in High Rainfall Areas of Taiwan
}

\author{
Keshav R. Adhikari \\ Institute of Agriculture and Animal Sciences (IAAS) Tribhuvan University, Rampur, Chitwan \\ e-mail: keshav.adhikari2008@gmail.com
}

\begin{abstract}
A 2-yr pot experiment conducted on an upland sandy clay loam soil in National Taiwan University, Taipei evaluated crop yields and mineral nitrogen $\left(\mathrm{N}_{\min }\right)$ leaching as affected by fertilizer application strategy, viz., inorganic (100\% $\mathrm{N}$ from urea), organic (100\% $\mathrm{N}$ from compost), combined (compost plus urea) and a zero control (Ctrl) treatments. Cabbage (Brassica oleracea L.) and corn (Zea mays L.) were grown in annual rotation under simulated high rainfall conditions. The $\mathrm{N}_{\min }$ leaching was monitored adding 83 and $62 \mathrm{~mm}$ of water fortnightly to cabbage and corn respectively for a total of 28 times. One-way ANOVA was used to determine the statistical significance of treatment effect and Tukey test for means comparisons $(p=0.05)$. Treatment differences were subtle for dry matter yields (DMY) but the treatments were strikingly different for 2 -yr cumulative $\mathrm{N}_{\min }$ leaching $(6.66 \%$ in organic, $30.6 \%$ in inorganic and $8.10 \%$ in combined treatments). This difference was largely related to the ability of soil to an increased retention of added $\mathrm{N}$ under organic and combined fertilization treatments. Unlike reported elsewhere, $\mathrm{N}$ recoveries were relatively high in compost applied soils, with or without urea fertilizer application. It is concluded that framers' practices of fertilization that has inherent problem of excessive $\mathrm{N}$ leaching in high rainfall areas of Taiwan could be improved by proper compost and urea combinations within agronomically recommended rate of $\mathrm{N}$ application.
\end{abstract}

Key words: swine manure compost, fertilization strategy, cabbage-crop rotation, acid soil

\section{Introduction}

While manure and manure compost offer an economical source of nutrients, mismanagement of these nutrients could lead to substantial $\mathrm{N}$ losses prior to crop uptake (Sullivan et al. 2005). Therefore, from environmental perspectives, repeated and/or heavy application of manure and manure compost in agriculture is questioned (Sharpley et al. 1996, Nelson et al. 2005). This ultimately requires lower levels of compost application and use of supplemental fertilizer to meet crop requirement while avoiding costly surplus of $\mathrm{N}$ and reducing $\mathrm{P}$ buildup in the soil (Sikora \& Enkiri 2001). Lower manure rates may probably indicate the range most farmers in developing countries can afford to apply to maintain soil fertility and sustain crop productivity. However, manure and manure compost literature does not tell clearly what the term 'lower rates' means to the growers. 
In practice, once compost is applied, most farmers in Taiwan heavily rely on chemical fertilizers for subsequent crops due to difficulty in handling and/or slow nutrient availability in manure/compost. Huang (1994) asserted that heavy uses of chemical fertilizers (particularly the N) in high rainfall areas of Taiwan have changed the soil nutrient balance and soils are degrading due to nutrient leaching. Although there has been an increase in application of manure compost to croplands in Taiwan, comparative studies of organic and inorganic sources of $\mathrm{N}$ fertilizers on $\mathrm{N}_{\min }$ leaching and crop uptake still seems poorly documented.

While theories support compost for reduced $\mathrm{N}$ leaching by greater retention (Tisdale et al. 1993), diversified sitespecific results make it often a debatable issue due to compost interaction with soil, crop and growing season weather conditions. High growing season rainfall in tropical Taiwan therefore appears another prominent factor with overriding effect on partitioning applied fertilizer-N. Numerous local studies have evaluated manure and compost effects on $\mathrm{N}$ uptake, crop yields and crop qualities in Taiwan (Chen 2004, Wang et al. 2005, Chung et al. 2006) but none evaluated effects on modifying rainfall impact on $\mathrm{N}_{\text {min }}$ leaching.

With increasing environmental awareness, not only the expression of crop uptake and leaching in absolute terms

Table 1. Initial characteristics of soil and compost used.

\begin{tabular}{lr|c|c|c}
\hline Measured properties & & Unit & Soil & Compost \\
\hline Texture & & - & Sandy clay loam & - \\
\hline & Sand & $\mathrm{g} \mathrm{kg}^{-1}$ & 475 & - \\
& Silt & $\mathrm{g} \mathrm{kg}^{-1}$ & 266 & - \\
Soil and compost pH & Clay & $\mathrm{g} \mathrm{kg}^{-1}$ & 249 & 6.9 \\
Electrical conductivity & - & 4.5 & 2.5 \\
Total nitrogen (N) & $\mathrm{dS} \mathrm{m}^{-1}$ & 0.6 & 37.3 \\
Inorganic N & $\mathrm{g} \mathrm{kg}^{-1}$ & 1.40 & 2009 \\
Organic carbon (C) & $\mathrm{mg} \mathrm{kg}^{-1}$ & 31.1 & 420 \\
Total phosphorus (P) & $\mathrm{g} \mathrm{kg}^{-1}$ & 13.8 & 36.3 \\
Water soluble P & $\mathrm{g} \mathrm{kg}^{-1}$ & 0.50 & 2700 \\
Bray-1 P & $\mathrm{mg} \mathrm{kg}^{-1}$ & 18.4 & - \\
Total potassium & $\mathrm{mg} \mathrm{kg}^{-1}$ & 29.9 & 3.80 \\
Total zinc & $\mathrm{g} \mathrm{kg}^{-1}$ & 5.60 & 92.7 \\
Total copper & $\mathrm{mg} \mathrm{kg}^{-1}$ & - & 28.4 \\
\hline \multicolumn{2}{l}{ Soil pH by 1:1 soil/water ratio, compost pH by 1:5 compost/water ratio (w/w). }
\end{tabular}

Soil $\mathrm{pH}$ by $1: 1$ soil/water ratio, compost $\mathrm{pH}$ by $1: 5$ compost/water ratio $(\mathrm{w} / \mathrm{w})$.

\section{Methodology}

\section{Soil and compost samples preparation}

Soils representing the surface $0-15 \mathrm{~cm}$ were sampled from the leveled upland agricultural area of Taoyuan (29 $59^{\prime} \mathrm{N}$ and $121^{\circ} 02^{\prime} \mathrm{E}$ ) located in Northern Taiwan. but also the knowledge of recovery of applied $\mathrm{N}$ has been important while dealing with organic versus inorganic fertilizers application. Existing literature document a great diversity of crop uptake and recovery which depends mainly on factors such as composition of fertilizer materials, methods of application, and biochemical characteristics of the soil. Globally, the N recovery from mineral fertilizer is about $50 \%$ (Eickhout et al. 2006), whereas $\mathrm{N}$ mineralization in compost varies greatly. He et al. (2000) observed $23.5 \%$ mineralization in 1 st-yr field incubation of compost, whereas it varied from 0 to over $50 \%$ in the 1 st growing season indicating that existing literature is not clear on this point (Passoni \& Borin 2009). Similarly, 1st-yr compost-N availability ranged from 2 to 44\% (Eghball \& Power 1999, Larney et al. 2006), and to $63 \%$ in manure (Motavalli et al. 1989).

With the above background, the objectives of this study were to evaluate the DMY, $\mathrm{N}$ uptake, $\mathrm{N}_{\min }$ leaching and recovery as affected by combinations of organic and inorganic fertilizer application strategy at agronomically recommended rate of $\mathrm{N}$ application. Year-round strong market was the major driving force for considering cabbage and corn as the test crops in this study. Although this is a short-term pot-experiment, results should assist establishing longer-term field-trials for considering potentials of DMY, crop uptake of $\mathrm{N}$ and leaching of applied $\mathrm{N}$ affecting manure compost management strategy in agriculture. 
Keshav R. Adhikari/Evaluating fertilizer.......

as Typic Udifluvent in US Soil Taxonomy. Soil samples were air-dried, mixed and sieved through a 10 mesh screen. Initial physico-chemical properties of soil are shown in Table 1 . Soil texture was analyzed by pipette method (Gee \& Bauder 1986). The standard Wagner pots ( $30 \mathrm{~cm}$ high and $25 \mathrm{~cm}$ diameter) were filled with $12.8 \mathrm{~kg}$ of soil (dry weight basis) which allowed sufficient space for holding the added water for conducting $\mathrm{N}_{\min }$ leaching test.

Compost (product registration number 0237001) was obtained from Chia-Yi County Compost Plant located in Southern Taiwan. It was made from swine manure and mushroom growing media (5:1 by vol.). Mushroom growing media had $95 \%$ wood flour and 5\% cereal flour. Air-dried compost samples were passed through a 10 mesh screen. Results of detailed compost sample analysis are also shown in Table 1 . The concentrations of total copper and zinc digested by aqua regia method in compost were found within the permissible limits (Taiwan Council of Agriculture 2007) for crop growth. For simplicity, swine manure compost is hereafter expressed as compost in this paper.

\section{Experimental design}

The pot experiment was conducted in National Taiwan University, Taipei from April 2006 to June 2008.
Cabbage and corn were grown in annual rotation for 2 -y. These crops in sequence, wherever appropriate, are referred to as Crop1, Crop2, Crop3 and Crop4 in this paper. Treatments included: Inorganic $(100 \% \mathrm{~N}$ from urea), Organic ( $100 \% \mathrm{~N}$ from compost), Combined (50\% $\mathrm{N}$ from compost plus $50 \% \mathrm{~N}$ from urea) and a Zero Control (Ctrl) for comparison. Each of inorganic and organic treatments applied $250 \mathrm{~kg} \mathrm{ha}^{-1}$ of $\mathrm{N}$, but in the latter case, $\mathrm{N}$ was supplied from $16 \mathrm{Mg} \mathrm{ha}^{-1}$ of composted manure with the assumption of $50 \% \mathrm{~N}$ mineralization in the year of application. Combined treatment applied $16 \mathrm{Mg} \mathrm{ha}^{-1}$ of composted manure plus urea, each supplying $250 \mathrm{~kg} \mathrm{ha}^{-1}$ of $\mathrm{N}$ in the mixture. Only crop1 received composted manure treatments, whereas crop 2 to crop4 received blanket of NPK from mineral sources to avoid deficiency of major plant nutrients. Actual amounts of compost, urea, monocalcium phosphate (MCP) and potassium chloride $(\mathrm{KCl})\left(\mathrm{g} \mathrm{pot}^{-1}\right)$ applied are shown in Table 2 . Nutrients were calculated on surface area basis and incorporated in the upper-half of the Wagner pots. Treatments were replicated four times and completely randomized to 16 Wagner pots. With four pots per table, 16 pots were then put on four movable tables ( $76 \mathrm{~cm}$ high X $69 \mathrm{~cm}$ wide $X 76 \mathrm{~cm}$ long). Pots were kept in the corners of each table to reduce plant competition for sunlight during growth.

Table 2. Quantities of compost, urea, $\mathrm{MCP}, \mathrm{KCl}$, and nutrients applied (recommended rate of NPK, 250:80:150 $\mathrm{kg} \mathrm{ha}^{-1}$, respectively) to crop1 and blanket of NPK applied to crop2 to crop4, April 2006 to June 2008.

\begin{tabular}{|c|c|c|c|c|c|}
\hline \multirow{2}{*}{$\begin{array}{l}\text { Crops in } \\
\text { sequence }\end{array}$} & \multirow{2}{*}{$\begin{array}{l}\text { Nutrient } \\
\text { source }\end{array}$} & \multicolumn{4}{|c|}{ Treatment } \\
\hline & & Ctrl & U250 & C250 & C250U250 \\
\hline \multirow{7}{*}{$\begin{array}{l}\text { Crop1 } \\
\text { (cabbage) }\end{array}$} & & & $\begin{array}{ll}----1 \\
-\cdots\end{array}$ & & \\
\hline & Compost & 0 & 0 & $80^{\dagger}$ & $80^{\dagger}$ \\
\hline & $\mathrm{N}$ from compost ${ }^{\ddagger}$ & 0 & 0 & 2.5 & 2.5 \\
\hline & P from compost ${ }^{\ddagger}$ & 0 & 0 & 2.42 & 2.42 \\
\hline & Urea $^{\S}$ & 0 & $2.71(1.25)$ & 0 & $2.71(1.25)$ \\
\hline & $\mathrm{MCP}^{\S}$ & 0 & $0.71(0.40)$ & 0 & 0 \\
\hline & $\mathrm{KCl}^{\S}$ & 0 & $1.20(0.80)$ & $0.60(0.40)$ & $0.60(0.40)$ \\
\hline \multirow{3}{*}{$\begin{array}{l}\text { Crop2 } \\
\text { (corn) }\end{array}$} & Urea & 0 & $1.30(0.60)$ & $1.30(0.60)$ & $1.30(0.60)$ \\
\hline & MCP & 0 & $0.36(0.20)$ & $0.36(0.20)$ & $0.36(0.20)$ \\
\hline & $\mathrm{KCl}$ & 0 & $0.33(0.20)$ & $0.33(0.20)$ & $0.33(0.20)$ \\
\hline \multirow{3}{*}{$\begin{array}{l}\text { Crop3 } \\
\text { (cabbage) }\end{array}$} & Urea & 0 & $1.89(0.87)$ & $1.89(0.87)$ & $1.89(0.87)$ \\
\hline & MCP & 0 & 0 & 0 & 0 \\
\hline & $\mathrm{KCl}$ & 0 & $1.19(0.72)$ & $1.19(0.72)$ & $1.19(0.72)$ \\
\hline \multirow{3}{*}{$\begin{array}{l}\text { Crop4 } \\
\text { (corn) }\end{array}$} & Urea & 0 & $1.30(0.60)$ & $1.30(0.60)$ & $1.30(0.60)$ \\
\hline & MCP & 0 & $0.36(0.20)$ & $0.36(0.20)$ & $0.36(0.20)$ \\
\hline & $\mathrm{KCl}$ & 0 & $1.32(0.80)$ & $1.32(0.80)$ & $1.32(0.80)$ \\
\hline
\end{tabular}

$80 \mathrm{~g} \mathrm{pot}^{-1}$ of compost corresponds to $16 \mathrm{Mg} \mathrm{ha}^{-1}$ of compost.

${ }^{*}$ Values shown are the total $\mathrm{N}$ and total $\mathrm{P}$ quantities that $80 \mathrm{~g} \mathrm{pot}^{-1}$ compost would automatically supply to the soil.

${ }^{\S}$ Urea, $\mathrm{MCP}$ and $\mathrm{KCl}$ are reagent grade chemicals. Values in parenthesis indicate elemental nutrients, not the fertilizer. MCP application in crop3 was missing. 
Purchased from a private nursery, the 1st-y cabbage (local cv.) seedlings were transplanted on April 15, 2006. Obtained from Tainan District Agricultural Research and Extension Station, corn seeds (Super Sweet cv.) were directly seeded on December 19, 2006 in the 1 st-y. Upon establishment, seedlings were thinned to one plant pot $^{-1}$ and the same plant density was maintained in the $2 \mathrm{nd}-\mathrm{y}$ rotation. Crops were grown at day and night temperatures of 30 and $25^{\circ} \mathrm{C}$, respectively in the greenhouse under ambient light conditions in the 1 st-y. Due to unavoidable circumstances, the pots were moved to the glass-house in the 2nd-y where temperature was not controlled and was obviously higher in the daytime than outside temperature. Since temperature can affect mineralization (Honeycutt et al. 1988, Watts et al. 2010) and influence leaching and crop growth, unavailability of glass-house temperature in the 2 nd-y caused to use outside temperatures (Figure 1) to facilitate the relevant discussions.

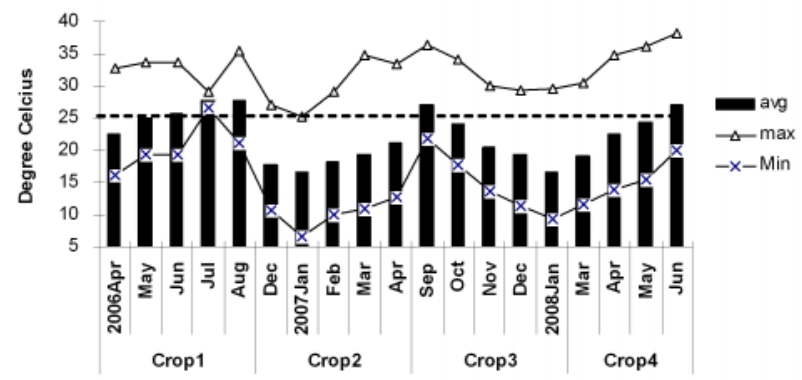

Fig. 1. Average, maximum and minimum monthly air temperatures $\left({ }^{\circ} \mathrm{C}\right)$ outside the green-house and glass-house during cabbage and corn growing seasons, April 2006 to June 2008. For a crop, months indicate the period between planting and harvesting. Dotted line at $25^{\circ} \mathrm{C}$ indicates a critical level beyond which denitrification starts increasing at slightly higher rates (Tisdale et al., 1993). Data source: Meteorological station of Department of Atmospheric Science located within $200 \mathrm{~m}$ radius of the experimental site in National Taiwan University, Taipei.

\section{Monitoring of $\mathrm{N}_{\min }$ leaching}

The monitoring of $\mathrm{N}_{\text {min }}$ leaching was carried out fortnightly during growing seasons. Each time when soil was leached, 4.01 of water for cabbage and 3.01 for corn was applied and allowed soils to be saturated for about 2-hr. Volumes in excess of saturation were received in containers below the Wagner's pots and ended the leaching test after the free-flow ceased practically. Leachate outflow volumes were then measured on a calibrated plastic jug. For each observation, about $300 \mathrm{ml}$ of outflow sample was collected in a clean and dry plastic bottle. Outflow samples were filtered with Whatman No. 42 and refrigerated at $4^{\circ} \mathrm{C}$ before analyzing for $\mathrm{N}_{\text {min }}$ leaching within a week. Leachate was analyzed by steamdistilling $10 \mathrm{ml}$ sub-sample using MgO-Devarda alloy (Mulvaney 1996). The amounts of $\mathrm{N}_{\min }$ leaching were then quantified by multiplying concentrations in leachate outflow by leachate volumes. These fortnightly leaching loads were then totaled to give the seasonal and 2-yr $\mathrm{N}_{\text {min }}$ leaching loads for each treatment. With four crops in 2-yr, soils were leached for a total of 28 times. In this high rainfall area, the purpose of series of leaching events was to separate the effects of time on leaching from those of treatments.

Water added to corn and cabbage for leaching corresponded to 1500 and $2000 \mathrm{~mm} \mathrm{y}^{-1}$ average annual rainfall depths, respectively. Given the fortnightly leaching frequency in one year, these values corresponded to $1500 / 24=62.5 \mathrm{~mm}$ and $2000 / 24=83.3$ $\mathrm{mm}$ rainfall depths each time leaching was carried out for corn and cabbage, respectively. Actual amounts of water added for each leaching event were computed by multiplying annual rainfall by surface area of the Wagner's pot divided by 24 leaching frequencies in a year. The difference in amounts of water applied for leaching during cabbage and corn seasons was based on the judgment of specific crop tolerance to water application and high spatial and temporal variations in rainfall in soil sampling area. We must mention that dissimilarities between soil and pot surface characteristics show the possibilities of water channeling down the inner pot-wall. However, allowing time enough to saturate the soil before outflow begins, use of greater volume of soil, and proper attendance during the leaching events were found useful for reducing this problem.

\section{Plant and soil chemical analysis}

At physiological maturity, aboveground plant parts were harvested, washed with deionized water, fresh weights taken, chopped into pieces and oven-dried $\left(65^{\circ} \mathrm{C}\right.$ for $\left.4 \sim 5 \mathrm{~d}\right)$ to a constant weight for recording dry matter yields. Dried and ground plant samples were stored in plastic bags until analysis for crop N uptake (Bremner \& Mulvaney 1982). Due to relatively higher fraction of clay, soil samples were passed through 100- 
mesh screen for total soil $\mathrm{N}$ analysis (Bremner \& Mulvaney 1982) expecting that grinding samples at higher mesh could improve recovery of the added $\mathrm{N}$.

The 2-yr cumulative crop $\mathrm{N}$ uptake, $\mathrm{N}_{\min }$ leaching and soil retention of applied $\mathrm{N}$ were also expressed in terms of apparent $\mathrm{N}$ recovery (ANR) calculated by the 'difference method' following Motavalli et al. (1989) as below:

ANR, $(\%)=[(\mathrm{N}$ in treatment $-\mathrm{N}$ in control $) /$ total $\mathrm{N}$ applied] x $100-(1)$

One-way ANOVA was used to test the significance of treatment effect on measured soil, crop and leachate variables (SAS Institute 2008). Treatment differences were compared using Tukey's Studentized Range (HSD) test $(P=0.05)$.

\section{Results}

\section{Nitrogen added to soil and dry matter yields}

Total $\mathrm{N}$ added to crops in 2-yr in Ctrl, inorganic, organic, and organic plus inorganic fertilizer combined treatments were 0,3220, 4570 and $5820 \mathrm{mg} \mathrm{pot}^{-1}$,

respectively (Table 2). It would be worth mentioning that crops in the 1st-yr rotation received much higher $\mathrm{N}(56 \%$ to $75 \%$ of the 2 -yr total, varied with treatment type) than in the 2 nd-yr rotation. It was because of no compost repetition in the 2 nd-year of crop rotation. However, the crops continued receiving blanket of $\mathrm{N}$ application also in the $2 \mathrm{nd}-\mathrm{yr}$ from mineral source which was approximately one-half of the recommended $\mathrm{N}$.

Table 3 presents data on effect of organic and inorganic fertilizers application on DMY of crops. In 4 of 4 crops in 2-yr, DMY responded significantly $(P<0.05)$ to treatments application. Average DMY $\left(\mathrm{g}\right.$ plant $\left.^{-1}\right)$ ranged between 26.5 and 42.5 in crop $1,28.7$ and 51.0 in crop2, 18.6 and 46.6 in crop3 and 17.9 and 58.9 in crop4. The DMY (42.5 to 58.9) of most crops were relatively superior in soils receiving combined application of inorganic and organic fertilizers, however the difference with other treatments was subtle. Contrarily, DMY in inorganic fertilizer treatment were mostly low and not different from Ctrl in the 1st-yr of crop rotation. In the 2nd-yr rotation, the inorganic fertilizer treatment produced the lowest DMY (18.6) of crop3 but recorded much higher DMY (49.1) in crop4.

Table 3. Effects of compost and urea application on dry matter yields (DMY) from crop1 to crop4, April 2006 to June 2008.

\begin{tabular}{|c|c|c|c|c|}
\hline Treatment & Crop1 & Crop2 & Crop3 & Crop4 \\
\hline \multicolumn{5}{|c|}{ - } \\
\hline Ctrl & $26.5 \pm 2.2 b$ & $28.7 \pm 4.3 b$ & $26.4 \pm 0.9 c$ & $17.9 \pm 0.9 \mathrm{c}$ \\
\hline $\mathrm{U} 250$ & $35.6 \pm 9.2 \mathrm{ab}$ & $36.2 \pm 5.2 b$ & $18.6 \pm 1.5 \mathrm{~d}$ & $49.1 \pm 5.7 \mathrm{~b}$ \\
\hline $\mathrm{C} 250$ & $31.1 \pm 7.6 \mathrm{ab}$ & $40.2 \pm 8.4 \mathrm{ab}$ & $46.6 \pm 3.6 \mathrm{a}$ & $53.1 \pm 2.1 \mathrm{ab}$ \\
\hline $\mathrm{C} 250 \mathrm{U} 250$ & $42.5 \pm 7.5 \mathrm{a}$ & $51.0 \pm 2.9 \mathrm{a}$ & $36.6 \pm 2.5 b$ & $58.9 \pm 2.2 \mathrm{a}$ \\
\hline$P>\mathrm{f}$ & $*$ & $* * *$ & $* * *$ & $* * *$ \\
\hline $\mathrm{CV}, \%$ & 20.9 & 14.3 & 7.34 & 7.27 \\
\hline LSD (0.05) & 14.9 & 11.7 & 4.94 & 6.83 \\
\hline
\end{tabular}

*,*** significant at 0.05 , and 0.001 probability levels, respectively. Within a column, means followed by the same letter are not significantly different (Tukey test, $P=0.05)$. Values are means \pm standard deviation $(n=4)$. Crop1 and crop3 indicate first and second-y cabbage. DMY of corn (crop2 and crop4) indicates combined weights of grain and biomass.

See Table 2 for treatment definitions.

\section{$\mathbf{N}$ uptake and $\mathbf{N}_{\min }$ leaching}

Table 4 presents data on effect of organic and inorganic fertilizer application on $\mathrm{N}$ uptake and $\mathrm{N}_{\text {min }}$ leaching. In 4 of 4 crops in $2-y r, N$ uptake and $\mathrm{N}_{\text {min }}$ leaching responded significantly $(P<0.05)$ to treatment application.

Average $\mathrm{N}$ uptake (in absolute term, mg plant ${ }^{-1}$ ) ranged between 286 and 1042 in crop1, 418 and 877 in crop2, 
357 and 1050 in crop3 and 124 and 513 in crop4. Despite treatment variations, large gaps in $\mathrm{N}$ uptake within a crop season were seen mainly due to the lowest $\mathrm{N}$ uptake in the $\mathrm{Ctrl}$ treatment relative to fertilizer-applied treatments. In terms of recovery ( $\%$ of added $N)$ that expresses $\mathrm{N}$ uptake by deducting uptake values in Ctrl from the uptake in the treatment, 2-yr mean values did not differ significantly $(P=0.05)$ among treatments (31.5 to $36.0 \%)$.

Similarly, average $\mathrm{N}_{\min }$ leaching (in absolute term, mg pot $^{-1}$ ) ranged between 136 and 589 in crop1, 148 and 318 in crop2, 81.4 and 489 in crop3 and 43.2 and 124 in crop4. In 3 of 4 crops, $\mathrm{N}_{\min }$ leaching was highest in soil receiving inorganic fertilizer application, whereas it was lower than in $\mathrm{Ctrl}$ in organic fertilizer application treatment during crop 1 . In terms of recovery (\% of added $\mathrm{N}$ ) that expresses $\mathrm{N}_{\min }$ leaching by deducting leaching values in Ctrl from the leaching in the treatment, 2-y mean values showed that organic fertilizer $(6.66 \%)$ as well as organic and inorganic fertilizer combined treatments $(8.10 \%)$, both reduced
$\mathrm{N}_{\text {min }}$ leaching effectively in comparison with high $\mathrm{N}_{\text {min }}$ leaching in inorganic fertilizer treatment (30.6\%).

\section{Discussion \\ The relationships between $\mathrm{N}$ addition, $\mathrm{N}$ uptake, $\mathrm{N}_{\text {min }}$ leaching and dry matter yields}

Correlation analysis of 2-yr cumulative data shows strong positive relationships of $\mathrm{N}$ addition with crop $\mathrm{N}$ uptake $(r=0.99 * * *)$ and dry matter yields $(r=$ $0.99 * * *)$ (data not shown). Results are consistent with many others (Hsieh 1995, Chung et al. 2002, TirolPardre et al. 2005) that increasing $\mathrm{N}$ additions improve $\mathrm{N}$ uptake and DMY, more in soils that receive combined application of inorganic and organic fertilizers, than in other soils with independent applications of organic or inorganic fertilizers. Although these findings do not reflect much newness in compost and mineral fertilizer research literature, it might still be interesting that increasing $\mathrm{N}$ application in this study showed a weak relationship with $\mathrm{N}_{\min }$ leaching $(r=0.30)$. This implies that under the given situation increasing $\mathrm{N}$ application, to a certain extent, would not produce high $\mathrm{N}_{\text {min }}$ leaching.

Table 4. Crop uptake of $\mathrm{N}$, apparent $\mathrm{N}$ recovery and $\mathrm{N}_{\min }$ leaching as affected by compost and urea application, April 2006 to June 2008.

\begin{tabular}{|c|c|c|c|c|}
\hline & \multicolumn{4}{|c|}{ Treatments } \\
\hline & Ctrl & U250 & C250 & C250U250 \\
\hline $\mathrm{N}$ added in $2-\mathrm{y}(\mathrm{mg} / \mathrm{pot})$ & 0 & 3320 & 4570 & 5820 \\
\hline \multicolumn{5}{|l|}{$\mathrm{N}$ uptake (mg/pot) } \\
\hline Crop1 & $286 \mathrm{c}$ & $615 b$ & $520 \mathrm{~b}$ & $1042 \mathrm{a}$ \\
\hline Crop2 & $418 \mathrm{c}$ & $617 \mathrm{bc}$ & $737 \mathrm{ab}$ & $877 \mathrm{a}$ \\
\hline Crop3 & $357 \mathrm{~d}$ & $563 \mathrm{c}$ & $1050 \mathrm{a}$ & $869 \mathrm{a}$ \\
\hline Crop4 & $124 \mathrm{~b}$ & $437 \mathrm{a}$ & $513 \mathrm{a}$ & $491 \mathrm{a}$ \\
\hline Sum of crop 1 to crop 4 & 1185 & 2232 & 2820 & 3279 \\
\hline $\mathrm{N}$ recovery in $2-\mathrm{y}(\%)^{\dagger}$ & - & $31.5 \mathrm{a}$ & $35.8 \mathrm{a}$ & $36.0 \mathrm{a}$ \\
\hline \multicolumn{5}{|l|}{$\mathrm{N}_{\min }$ leaching $(\mathrm{mg} / \mathrm{pot})$} \\
\hline Crop1 & $229 b$ & 589 a & $136 \mathrm{~b}$ & $265 \mathrm{~b}$ \\
\hline Crop2 & $148 \mathrm{~b}$ & $318 \mathrm{a}$ & $247 \mathrm{ab}$ & $280 \mathrm{ab}$ \\
\hline Crop3 & $81.4 \mathrm{c}$ & $489 \mathrm{a}$ & $297 \mathrm{~b}$ & $320 \mathrm{~b}$ \\
\hline Crop4 & $43.2 \mathrm{~b}$ & $120 \mathrm{a}$ & $124 \mathrm{a}$ & $105 \mathrm{ab}$ \\
\hline Sum of crop 1 to crop4 & 501 & 1516 & 804 & 970 \\
\hline $\mathrm{N}_{\min }$ leaching in 2-y $(\%)^{\ddagger}$ & - & $30.6 \mathrm{a}$ & $6.60 \mathrm{~b}$ & $8.10 \mathrm{~b}$ \\
\hline Total soil $\mathrm{N}$ in 2-y (mg/pot) & $14928 \mathrm{~b}$ & $15599 \mathrm{~b}$ & $16860 \mathrm{a}$ & $16984 \mathrm{a}$ \\
\hline Applied $\mathrm{N}$ left in soil in $2-\mathrm{y}$ & - & 671 & 1932 & 2056 \\
\hline Retention of applied $\mathrm{N}(\%)^{\S}$ & - & $20.2 \mathrm{~b}$ & $42.3 \mathrm{a}$ & $35.3 \mathrm{ab}$ \\
\hline Unaccounted for $\mathrm{N}(\%)^{\mathrm{T}}$ & - & $17.7 \mathrm{a}$ & $15.3 \mathrm{a}$ & $20.6 \mathrm{a}$ \\
\hline
\end{tabular}

Values in a row for a parameter with the same letter are not significantly different (Tukey test, $P=0.05$ )

[ (Sum of $\mathrm{N}$ uptake by 4 crops in the treatment $-\mathrm{N}$ uptake in the control) / Total amount of $\mathrm{N}$ added to the treatment] $\mathrm{x} 100$. $*$ [ Sum of $\mathrm{N}_{\text {min }}$ leaching during 4 crop seasons from the treatment $-\mathrm{N}_{\min }$ leaching from the control) / Total amount of $\mathrm{N}$ added to the treatment] $x 100$.

$\S$ [(Total soil $\mathrm{N}$ in the treatment - total soil $\mathrm{N}$ in the control) / Total amount of $\mathrm{N}$ added to the treatment] $\mathrm{x} 100$. I[ (Total added $\mathrm{N}$ - leached $\mathrm{N}_{\min }-$ crop uptake of $\mathrm{N}$ - soil retention of $\mathrm{N}$ ) / Total amount of $\mathrm{N}$ added to the treatment] $\mathrm{x}$ 100.

See Table 2 for treatment definitions. 
A closer observation would show that in 4 of 4 crops, $\mathrm{N}_{\text {min }}$ leaching in organic fertilizer treatments with or without inorganic fertilizer (C250U250 and C250) were not statistically different with each other (Table 4). Here seems to be the greater effect of compost where most $\mathrm{N}$ occurs in organic form which is not readily available for leaching or crop uptake. The findings are congruent with Jokela (1992) who observed reduced leaching from composted soils compared with equivalent $\mathrm{N}$ rates from chemical fertilizers. Contrarily, the treatments that applied low $\mathrm{N}$ in inorganic fertilizer contributed to the highest amounts of $\mathrm{N}_{\min }$ leaching. It could be attributed to the form in which $\mathrm{N}$ is readily available in urea for leaching or crop uptake (Munoz et al. 2003). These results clearly indicate that in high rainfall areas, application of organic fertilizers with or without inorganic fertilizers would be more beneficial than applying inorganic fertilizer alone.

\section{The relationships between $N$ addition, $N_{\text {min }}$ leaching and recovery of applied $\mathbf{N}$}

Analysis of 2-yr cumulative data shows that increasing $\mathrm{N}$ addition from 3320 to $5820 \mathrm{mg} \mathrm{pot}^{-1}$ did not bring statistical differences in apparent crop $\mathrm{N}$ recovery among treatments ( 31.5 to $36 \%$ in excess of the control) (Table 4). These compare with 30 to $40 \% \mathrm{~N}$ recovery from urea application under rice field (Craswell et al. 1981), 36\% apparent $\mathrm{N}$ efficiency under sorghum (Schlegel 1992) and 28 to $73 \%$ fertilizer N recovery under sweet corn and potato using the difference method (Bundy \& Andraski 2005). Although crop N recovery in inorganic fertilizer treatment $(30.6 \%)$ was statistically at par with organic fertilizer treatments, it produced objectionably high $\mathrm{N}_{\min }$ leaching $(30.6 \%)$ in comparison with much reduced leaching recovery observed in organic fertilizer treatments (6.60 to 8.10\%). Despite similar $\mathrm{N}$ uptake recovery between organic and organic plus inorganic fertilizer treatments, slightly lower $\mathrm{N}$ retention in soil was seen in the latter. For a similar situation Han et al. (2004) explain that urea blending with compost provides mineral-N for increased net mineralization of compost- $\mathrm{N}$, more prominent in soils with relatively low organic-carbon. Conversely, the reason of lower $\mathrm{N}$ recovery in organic fertilizer treatment is partly explained by recent advances in mineralization where bulk of organic- $\mathrm{N}$ is believed to be held in complexly bonded polypeptide labile forms rendering $\mathrm{N}$ to be slowly available (Olk 2008).
The literature reviewed in this paper shows that crop $\mathrm{N}$ recovery can vary over a wide range. While it can be as high as $73 \%$ in inorganic fertilizer applied soils (Bundy \& Andraski 2005), much lower recoveries are recorded in compost-amended soils $(<15 \%)$ in the 1 st$\mathrm{y}$ of application both in pot and field studies (Hartz \& Giannini 1998, Eghball \& Power 1999, Munoz et al. 2008). Those who study crop $N$ uptake and recovery mostly do not monitor $\mathrm{N}_{\min }$ leaching but the present study also includes direct observation of the latter. Therefore, results should be more meaningful as they reflect simultaneous crop $\mathrm{N}$ uptake and leaching behavior of the soil under high rainfall during growing seasons. In view of these reviews and results of the present study, combined crop $\mathrm{N}$ uptake and $\mathrm{N}_{\text {min }}$ leaching recoveries in any treatment are not low in this study. It would also be interesting that relatively high recoveries occurred despite frequent wetting of soil for leaching operations which would have affected microbial growth adversely by creating a sub-optimal soil chemical environment for $\mathrm{N}$ transformation. The processes of soil microbial transformation such as mineralization and nitrification are reduced in wet soils with moisture contents exceeding $1 / 3$ bar or field capacity (Tisdale et al. 1993). With increasing soil wetness, it seems reasonable that more of the mineral $\mathrm{N}$ becomes available for leaching and the reduced soil condition renders root uptake of $\mathrm{N}$ weaker. Therefore, it appears that most crop $\mathrm{N}$ uptake occurs during aerated soil phase (time between two consecutive leaching events during growing season) and $\mathrm{N}_{\min }$ leaching occurs during wet soil phase (time periods between two consecutive aerated soils phases when leaching are monitored from saturated soils).

Non-repeated application of organic fertilizer (swine manure compost in this case) and inorganic fertilizer (urea in this case) to cabbage and corn crops in 2-y produced dry matter yields, where differences among treatments were mostly subtle. Not reported elsewhere in compost literature, the results of this study show that $\mathrm{N}$ recovery from the application of swine manure compost with or without inorganic $\mathrm{N}$-fertilizer (C250 and C250U250) can be high in this soil. Relatively higher recoveries in these treatments should have been not only due to the compost composition and soil characteristics, but also due to hot and humid environment conducive for improved compost-N mineralization and availability. Quite fascinating and promising are these results from the perspectives of 
Nepal Journal of Science and Technology 12 (2011) 7-16

maintaining environmental quality from reduced $\mathrm{N}_{\min }$ leaching. However, a field-scale study would be useful to validate the applicability of these results.

\section{Acknowledgements}

The study was funded by National Science Council (NSC), Executive Yuan, Government of Taiwan, Grant No. NSC 95-2313-B-002-075-MY3 and NSC 96-2621-B002-021. The Soil Survey and Remediation Laboratory staff at the Department of Agricultural Chemistry, National Taiwan University, is thankful for providing the assistance for this work.

\section{References}

Bremner, J.M. and C.S. Mulvaney. 1982. Salicylic acidthiosulfate modification of Kjeldahl method to include nitrate and nitrite. In: Methods of Soil Analysis. Part 2. Agronomy No. 9, 2nd Ed. (Eds. A.L. Page, R.H. Miller and D.R. Keeney). American Society of Agronomy, Madison, WI, Pp. 621-622.

Bundy, L.G. and T.W. Andreski. 2005. Recovery of fertilizer $\mathrm{N}$ in crop residues and cover crops on an irrigated Soil Sci. Soc. Am. J. 69:640-648.

Chen, J.H. 2004. Effect of compost on the availability of nitrogen and phosphorus in strongly acid soils. $J$. Chinese Soc. Soil Fert. Sci. 7:115-122.

Chung, R.S., C.H. Wang, C.W. Wang, W.Y. Deng, H.H. Huang and S.M. Hsieh. 2002. Growth and NPK uptake by corn and rice crops under different nitrogen fertilizer management for six years. In: Proceedings of agriculture, soil ecology quality and productivity (Ed. C.C. Young). Department of Soil and Environmental Sciences, National Chung Hsiung University, Taichung, Taiwan, pp.161-180.

Chung, R.S., Z.S. Chen and S.L. Huang. 2006. Growth and nitrogen composition of cabbage under high application rate of hug dung compost. Taiwanese J. Agric. Chem. Food Sci. 44:263-271.

Craswell, E.T., S.K. De Datta, M. Hartantyo and W.N. Obcemea. 1981. Time and mode of nitrogen fertilizer application to tropical wetland rice. Fert. Res. 2:247-259.

Eghball, B. and J.F. Power. 1999. Phosphorus- and nitrogenbased manure and compost applications: corn production and soil phosphorus. Soil Sci. Soc. Am. J. 63:895-901.

Eickhout, B., A.F. Bouwman and Z.H. Van. 2006. The role of nitrogen in world food production and environmental sustainability. Agri. Ecosys. Environ. 116:4-14.

Gee, G.W. and J.W. Bauder. 1986. Particle-size analysis. In: Methods of Soil Analysis, Part 1. Agronomy. 2nd Ed. (Eds. A. Klute, G.S. Campbell, R.D. Jackson, M.M. Mortland and D.R. Nielsen). American Society of Agronomy, Madison, WI. pp. 383-411.
Han, K.H., W.J. Choi, G.H. Han, S.I. Yun, S.H. Yoo and H.M. Ro. 2004. Urea-nitrogen transformation and compost-nitrogen mineralization in three different soils as affected by the interaction between both nitrogen inputs. Biol. Fertil. Soils. 39:193-199.

Hartz, T. and C. Giannini. 1998. Duration of composting of yard wastes affects both physical and chemical characteristics of compost and plant growth. HortScience 33:1192-1196.

He, Z.L., A.K. Alva, P. Yan, Y.C. Li, D.V. Calvert, P.J. Stoffella and D.J. Banks. 2000. Nitrogen mineralization and transformation from composts and biosolids during field incubation in a sandy soil. Soil Sci. 165:161-169.

Honeycutt, C.W., L.M. Zibilske and W.M. Clapham. 1988. Heat units for describing carbon mineralization and predicting net nitrogen mineralization. Soil Sci. Soc. Am. J. 52:1346-1350.

Hsieh, S.C. 1995. Technology for sustainable agriculture in Taiwan: Grain and root crops production and cultural practices. In: Sustainable Food Production in the Asian and Pacific Region, Book Series No. 46. Food and Fertilizer Technology Center (FFTC) for the Asian and Pacific Region, Wenchow St., Taipei, Taiwan. Pp. 5-21. Available from http://www.fftc.agnet.org/library

Huang, S.N. 1994. Soil management for sustainable food production in Taiwan. Extension Bull. Series No. 390. 13 pp. available from http://www.agnet.org/library/eb/ 390

Jokela, W.E. 1992. Nitrogen fertilizer and dairy manure effects on corn yield and soil nitrate. Soil Sci. Soc. Am. J. 56:148-154.

Larney, F.J., D.M. Sullivan, K.E. Buckley and B. Eghball. 2006. The role of composting in recycling manure nutrients. Can. J. Soil Sci. 86:597-611.

Motavalli, P.P., K.A. Kelling and J.C. Converse. 1989. Firstyear nutrient availability from injected dairy manure. J. Environ. Qual. 18:180-185.

Mulvaney, R.L. 1996. Nitrogen-inorganic forms. In: Methods of Soil Analysis, Part 3. Chemical Methods, SSSA Book Series No. 5. (Eds. D.L. Sparks, A.L. Page, P.A. Helmke, R.H. Loeppert, P.N. Soltanpour, M.A. Tabatabai, C.T. Johnston and M.E. Sumner). Soil Sci. Soc. Am. and Am. Soc. Agron., Madison, WI. pp. 1123-1184.

Muñoz, G.R., J.M. Powell and K.A. Kelling. 2003. Nitrogen budget and soil nitrogen dynamics after multiple applications of unlabeled or ${ }^{15} \mathrm{~N}$-enriched dairy manure. Soil Sci. Soc. Am. J. 67:817-825.

Muñoz, G.R., K.A. Kelling, K.E. Rylant and J. Zhu. 2008. Field evaluation of $\mathrm{N}$ availability from fresh and composted manure. J. Environ. Qual. 37:944-955.

Nelson, N.O., J.E. Parsons and R.L. Mikkelsen. 2005. Fieldscale evaluation of phosphorus leaching in acid sandy soils receiving swine waste. J. Environ. Qual. 34:20242035. 
Olk, D.C. 2008. Organic forms of soil nitrogen. In: Nitrogen in Agricultural Systems. Agronomy Monograph 49. ASA-CSSA-SSSA (Eds. J.S. Schepers \& W.R. Raun) Madison, WI. pp 57-100.

Passoni, M., and M. Borin. 2009. Effects of different composts on soil $\mathrm{N}$ balance and dynamics in a biennial crop succession. Compost Sci. Util.17:108-116.

SAS Institute. 2008. JMP Statistics and Graphics Guide, Version 9.1, Cary, NC. USA.

Schlegel, A.J. 1992. Effect of composted manure on soil chemical properties and nitrogen use by grain sorghum. J. Prod. Agric. 5:153-157.

Sharpley, A.N., T.C. Daniel, J.T. Sims and D.H. Pote. 1996. Determining environmentally sound soil phosphorus levels. J. Soil Water Conserv. 51:160-166.

Sikora, L.J. and N.K. Enkiri. 2001. Uptake of ${ }^{15} \mathrm{~N}$ fertilizer in compost-amended soils. Plant Soil. 235:65-73.

Sullivan, D.G., C.W. Wood, W.F. Owsley, M.L. Norfleet, B.H. Wood, J.N. Shaw and J.F. Adams. 2005. Denitrification following land application of swine waste to Bermudagrass pasture. Commun. Soil Sci. Plant Anal. 36:1277-1288.

Taiwan Council of Agriculture. 2007. Regulations for heavy metals, fertilizer and compost in Taiwan, Taipei, Taiwan.
Tirol-Padre, A., K. Tsuchiya, K. Inubushi and J.K. Ladha. 2005. Enhancing soil quality through residue management in a rice-wheat system in Fukuoka, Japan. In: Proceedings of the International Conference of the 7th East and Southeastern Federation of Soil Sci. Soc. (ESAFS) on Sustainability of Paddy Farming Systems. (Eds. C.P. Aganon \& R.B. Carating). Bureau of Soils and Water Management, Quezon city, Philippines, pp. 442-445.

Tisdale, S.L., W.L. Nelson, J.D. Beaton and J.L. Havlin. 1993. Soil and fertilizer nitrogen. In: Soil Fertility and Fertilizers. 5th Ed. (Eds. P.F. Corey). Macmillan Publishing Co., 866 Third Avenue, NY. Pp. 109-175.

Wang, C.H., L.J. Chiu, Y.W. Lin and M.H. Tsao. 2005. Effects of long term farming method on nitrogen efficiency, crop growth and soil properties. In: Proceedings of the Chinese Soc. Soil Sci. (Ed. R.S. Chung). Department of Agricultural Chemistry, National Taiwan University, Taipei, Taiwan, pp. 113-146.

Watts, D.B., H.A. Torbert and S.A. Prior. 2010. Soil properties and landscape position effects on seasonal nitrogen mineralization of composted dairy manure. Soil Sci. 175:27-35. 
Nepal Journal of Science and Technology 12 (2011) 7-16 